Subjective wellbeing and interior architecture: why and how the design of interior spaces can enable activities contributing to people's subjective wellbeing Peer-reviewed author version

PETERMANS, Ann (2019) Subjective wellbeing and interior architecture: why and how the design of interior spaces can enable activities contributing to people's subjective wellbeing. In: Journal of design research (Print), 17(1), p. 64-85.

Handle: http://hdl.handle.net/1942/29107 


\title{
Subjective wellbeing and interior architecture: why and how the design of interior spaces can enable activities contributing to people's subjective wellbeing
}

\author{
Author's name: Ann Petermans \\ Author's institution: Hasselt University, Faculty of Architecture and Arts (Belgium) \\ Author's email address: ann.petermans@uhasselt.be \\ Author's mailing address: \\ Hasselt University \\ Faculty of Architecture and Arts \\ Ann Petermans \\ Agoralaan Building E \\ 3590 Diepenbeek (Belgium)
}

Biographical statements: Ann Petermans is affiliated to the Faculty of Architecture and Arts of Hasselt University, Belgium. Her research interests pertain in particular to designing for experience in designed environments and for diverse user groups, and research related to design for subjective well-being in architecture and interior architecture.

Ann chairs the Design Research Society's Special Interest Group on Design for Wellbeing, Happiness and Health. She has presented her work at various national and international conferences, reviews manuscripts for several journals, and is editorial board member of The Design Journal. Currently, together with prof. Cain (Loughborough University, UK), she is finishing a book for Routledge which will be entitled 'Design for Wellbeing: an applied approach'. 


\title{
Subjective wellbeing and interior architecture: why and how the design of interior spaces can enable activities contributing to people's subjective wellbeing
}

\begin{abstract}
Can interior and architectural design contribute to people's subjective wellbeing? And can interior architects be supported to design interior environments that enable people to flourish in the interior environments wherein they reside? This paper elaborates on design for subjective wellbeing in interior architecture, and is organized in three sections. After discussing experience and the rise of attention for wellbeing in interior architecture, a theoretical section demonstrates why it is relevant and highly valuable for interior architects to work on the design of interiors that enable people to work on their subjective wellbeing. Via a review of literature, the semantics of wellbeing in interior architecture are discussed, whereby it is demonstrated how interior architecture can be considered as a circumstantial factor surrounding people all the time, providing a platform that enables people to work on their wellbeing. Next, we reflect on the question of how interior architects can be triggered to design for wellbeing. Starting from Lyubomirsky's happiness-enhancing strategies (2007) and the characteristics of positive design as proposed by Desmet and Pohlmeyer (2013), it is demonstrated how these theoretical insights can be translated into diverse interior architectural design projects which all offer people opportunities to work on their subjective wellbeing. The paper concludes with a reflection on the contribution that interior architecture can have to enable people to 'be well' in a diverse range of interior environments wherein they (need to) function or reside. It also stresses the importance to take specifics proper to one's proper discipline into account when aiming to design for subjective wellbeing.
\end{abstract}

Keywords - Interior Architecture, Subjective Wellbeing, Enabling activities, Positive Design

Relevance to design practice - the theoretical insights and discussed design projects demonstrate the potential of interior architecture to enable people to work on their subjective wellbeing in a diverse range of interior environments wherein they (need to) reside. 


\section{Introduction}

From time to time, I love to go to our family's country house, that is located in the midst of a forest, on a high hill. The house finds itself truly in-between the trees and bushes of the forest. The house is constructed in Finnish pine-tree wood, and is designed, constructed and spatially organized while taking into account as much as possible ecologically sustainable and wellbeing considerations. The interior and furnishings that are present concern rather necessary items, as the aim of the house's constructors was to bring its guests 'back to basics' and truly focus on each other. In the interior, next to a small and humble kitchen, toilets and bathroom, there are firm tables, comfortable seats and chairs, beds and cupboards present throughout the house. Decoration is modest, and heating has to be done by lighting one's own fire in a stove that is placed in the heart of the house. There is no internet access; the radio and television connection are of bad quality given the omnipresence of the forest all-around the house and the lack of good satellite connections. But, in my experience and the experiences of my dearest, this house feels truly cozy and warm, and brings its temporary inhabitants truly close to one another: when we reside here, this is 'our place', a place that enables us to temporarily escape the busyness of everyday life and truly focus on one another and have close connections and deep talks. Here, people can truly come at ease, and enjoy performing various kinds of activities they love.

This personal experience can make people wonder which aspects there are that contribute to people's wellbeing in a particular place. Can the design of interior and architectural elements impact on people's wellbeing? And can architecture and interior architecture help, or even stimulate people to flourish in an environment? This paper elaborates on design for wellbeing in interior architecture first, by indicating why it is relevant for interior architects to design for wellbeing. Hereafter, we reflect on the question of how interior architects can try to design for wellbeing. By combining theoretical findings with insights coming forth from design practice, the paper aims to point to the contribution that interior architecture can have to enable people to work on their subjective wellbeing in a diverse range of interior environments wherein they live, function or reside.

Interior architecture in essence always focuses on the relationship between a person and an environment. In interior design practice, it seems evident that the interaction between the human body and the environment wherein they reside, steers designers (Edwards, 2011). As a consequence, for architects and interior architects, it seems crucial to empathize with users and clients' emotions and experiences. However, to date, it can be cautiously suggested that empathy is still not always mainstream in these disciplines (Denson, 2017; Verhulst et al., 2016), although renowned architectural thinkers as well as practicing architects such as for instance Peter Zumthor, Juhani Pallasmaa and Alberto Pérez-Gomez have already often pointed at the relevance and importance of empathy, experience and the way in which meaning can be given through experiences in a designed environment. Indeed, taken into account the growing attention for subjective wellbeing in design, empathizing seems to be crucial in understanding others, relating to them and being sensitive to their emotions and experiences. 
However, up to a few years ago, academic studies focusing on the topic of experience from an interior architectural perspective were mainly lacking. The last few years, there have appeared some studies aiming to fill in this gap (e.g., see Sloane, 2014; Steen, 2016; Petermans et al., 2013), also from researchers from related disciplines that reflect about experiences in interior architectural environments (e.g., Seamon, 2012; Seamon and Gill, 2015). However in general, there seems to be a much wider array of possibilities to further elaborate on experiences and their 'potential' from an interior architectural perspective than has been done up to date. Reading Bollnow's 'Human Space' (2011) inspired the author in this respect. In his book (2011, p. 275), Bollnow states that 'the intimate relationship of humans and their house is however shown not only in the fact that we are able to impress the character of our own nature on our dwelling space, and conversely the latter has its effect on us, but equally in the way in which we in our nature are determined by our environment, and our nature is transformed according to the nature of our environment'.

This citation illustrates not only the possibilities that interiors offer to study human experiences at a particular place. It also inspired us to take the issue of experience one step further, so that - in my viewpoint - a new key question or 'challenge' can be formulated for the discipline of interior architecture: can interior architects be enabled to design interior environments that contribute to people's subjective wellbeing?

Before this question can be answered, it is important to elaborate on considerations relating to wellbeing that interior architects (need to) take into account when designing an interior environment.

\section{Wellbeing and Interior Architecture}

\section{Wellbeing semantics}

Up to date, when designers working on the design of interiors would be reflecting about happiness and wellbeing in interior environments, their focus would mainly be on issues relating to the fulfillment of objective conditions of the environments where people reside. Typical questions in this respect are, for instance: is there enough daylight present? How is the circulation throughout the space? Is the space energy efficient?

Currently however, the focus in interior architecture is shifting (Petermans \& Pohlmeyer, 2014; Petermans \& Nuyts, 2016). As the boundaries of consumerism, capitalism, and commercialism in various countries seem to have been attained, many people's mindset is shifting, and all the more people seem to be ready to look for something else ; they want to experience more 'meaning', in a very broad sense (Welzer, 2014). These changing conditions are an important breeding ground to the shift that is upcoming in interior architecture: a shift from attention for 'objective wellbeing' to 'subjective wellbeing'.

Indeed, currently, due to the spirits of our times, different researchers in interior architecture are starting to reflect about the question how the built environment can contribute to users' wellbeing or happiness (e.g., Smith et al., 2012; Petermans \& Pohlmeyer, 2014). Taken into account the fact that 
many people all over the world currently struggle with the rat race of everyday life, resulting in various issues with regards to mental and physical health and a lot of 'unhappy people' (see also Veenhoven, 2011, 2016), it seems truly challenging for interior architects and researchers in our field to wonder about the following questions: can interior architects design environments that trigger people to undertake meaningful activities that enable them to work on their wellbeing? And if so, how can they do this? In what follows, answers to these questions are proposed.

To date, a shared conceptualization of what wellbeing entails, is lacking, both in disciplines other than design that focus on wellbeing and happiness (Diener, 2000; Lyubomirsky, 2007; Sheldon and Lyubormirsky, 2007; Seligman, 2011; Lee et al., 2011; Verhofstadt et al., 2015; Veenhoven, 2011, 2016), as well as in design disciplines itself that focus on the topic (Petermans \& Pohlmeyer, 2014; Petermans \& Nuyts, 2016). Consequently, the terms of 'subjective wellbeing' (SWB) and 'happiness' have often been used interchangeably (Lyubomirsky, 2007; Lee et al., 2011; Veenhoven, 2011; Desmet \& Hassenzahl, 2012; Verhofstadt et al., 2015). In this paper, the author follows suit.

The way wherein SWB is often connoted is close to the way wherein most people fill in 'happiness' in its widest sense, that is, happiness as an overarching term for 'all that is good' (Veenhoven, 2011, p. 2). Looking at its epistemological background, 'happiness' is the common translation of what Aristotle called 'eudaimonia' (Encyclopedia Britannica, 2013), whereby 'eu' is the Greek word for 'good' and 'daimon' refers to 'spirit'. 'Eudaimonia' refers to the living of one's life to its full potential; 'to life well'. Eudaimonia was a central concept in ancient Greek ethics, whereby philosophers reflected about the question of how to achieve eudaimonia. Today, more than 2300 years later, various researchers in diverse domains still wonder about the same question.

Focusing on the study of happiness from an interior perspective is important, as research has demonstrated that being and feeling happy truly makes people feel better, more energetic and physically healthier. Happy people are also more creative, open-minded and are more productive in their jobs (Lyubormirsky et al., 2005, Veenhoven, 2011). As such, striving for more happy people not only seems to be relevant for individuals, but also for society as a whole (Desmet and Hassenzahl, 2012 ; Hassenzahl et al., 2013). As such, it seems to offer truly interesting and challenging opportunities for interior architecture.

\section{Determinants of Happiness: Genetics, Life Circumstances and Intentional Activities}

In 2005, Lyubomirsky, Sheldon and Schkade, renowned authors in positive psychology, published a seminal article wherein they identified three determinants of happiness. In their view (see figure 1), $50 \%$ of variance in inter-individual happiness can be explained by the presence of a predetermined genetic set-point. Next, life circumstances (10\%) and intentional activities (40\%) contribute to the variance in a person's happiness level. 


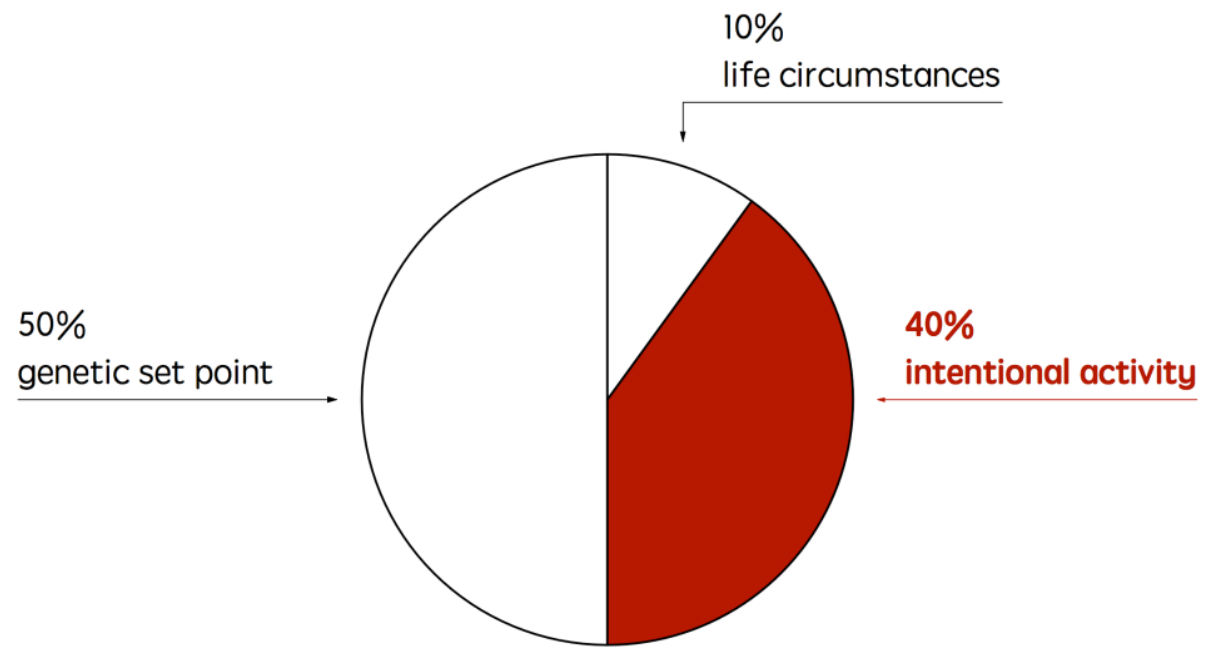

Figure 1. What determines happiness?

Source: Lyubomirsky et al., 2005

'Genetics' is a factor that is stable over time, and mostly immune to be influenced (Lykken and Tellegen, 1996). 'Life circumstances' concern factors that occur in the course of a person's life, and mostly relate to issues that help to answer the question of what people have to face in the course of their lives. Occupational status, health status, marital status, religious affiliation are examples in this respect. As Figure 1 illustrates, such factors contribute to happiness, but only to a relatively small extent. This brings us to 'intentional activities'. In Lyubomirsky's view (2005, 2007), such activities relate to a person's behavior, which is a factor that is within a person's ability to control. In other words, by focusing on activities, people have the ability to deliberately choose to work on their happiness through particular choices they make in the course of their lives, that is, what they do in their lives, and how they think.

In her book 'The how of happiness', Lyubomirsky (2007) introduced 12 strategies or 'activities' that can help to increase a person's happiness.

\begin{tabular}{|l|l|ll|}
\hline Expressing gratitude & Cultivating optimism & $\begin{array}{l}\text { Avoiding overthinking and } \\
\text { social comparison }\end{array}$ \\
\hline Practising acts of kindness & Nurturing social relationships & $\begin{array}{l}\text { Developing strategies for } \\
\text { coping }\end{array}$ \\
\hline Learning to forgive & Increasing 'flow' experiences & Savouring life's joys \\
\hline Committing to your goals & $\begin{array}{l}\text { Practising religion and } \\
\text { spirituality }\end{array}$ & Taking care of your body \\
\hline
\end{tabular}

Figure 2. Happiness-increasing strategies

Source: Lyubomirsky, 2007

Not all strategies mentioned in Figure 2 are relevant for all individuals, as we all have unique needs, 
wishes, values, interests and resources which undoubtedly influence our preference for some happiness-enhancing strategies over others. As a consequence, it is highly relevant to strive for a good 'person-activity fit', so that people can engage in activities that are meaningful and appropriate for them. If an activity can succeed in being perceived as such, people's motivation to engage and participate in the concerned activity will augment. Research in psychology on happiness-increasing strategies has demonstrated that such activities have an effect on a person's happiness, both in the short and in the long term (Sin and Lyubomirsky, 2009; Lyubomirsky and Layous, 2013).

In positive psychology, different approaches have been suggested by which individual happiness may be fostered. To date however, an interior architectural translation hereof is missing. Therefore in this paper, it will be investigated whether focusing on an interior architectural 'translation' of a selection of the happiness-enhancing strategies that Lyubomirsky (2007) proposes, adds knowledge to the body of theory on design for wellbeing in interior architecture.

\section{Positive Design}

In 2013, Desmet and Pohlmeyer introduced 'Positive Design' to the design community, which they described as being 'an umbrella term for all forms of design, design research and design intention in which explicit attention is paid to the effects of design on the subjective wellbeing of individuals and communities' (p. 6).

Their article was the first to translate insights originating in positive psychology and philosophy regarding wellbeing, to design disciplines. The Positive Design Framework was presented here, comprising three components to design for people's wellbeing which together should allow people to flourish: design for pleasure, personal significance, and virtue.

Design for pleasure concerns the experience and feelings of happiness that is realized by focusing on the totality of a person's pleasures, that occur in the moment, here and now. Design for personal significance relates to happiness that comes forth from personal meaning, and focuses on personal goals or ambitions. Design for virtue addresses happiness that results from virtuous behavior. Design for human flourishing is where the three components intersect and are in balance with one another, as all three are necessary ingredients to contribute to a person's flourishing. Positive Design is distinct from other related design approaches in its explicit focus on enabling and / or stimulating human flourishing.

In the paper, Desmet and Pohlmeyer (2013) call for the development of tailored design approaches in various design disciplines. In order to do so, five characteristics of positive design are put forward to consider: one needs to strive for a personal fit and a balance between the different components of the positive design framework. Next, the design should offer a means for long-term impact and should be possibility-driven. Finally, it should encourage active user involvement.

In the last section of their paper, Desmet and Pohlmeyer (2013) outlined different design research 
challenges, among which the issue of developing design approaches and methods on positive design that designers in a diverse range of design disciplines can apply. Therefore this paper tries to demonstrate the value that positive design can have for interior architects, because specifically in the domain of interior architecture, explicitly studying and designing interior environments from the perspective of subjective wellbeing is a new topic of interest. Developing an interior architectural 'translation' of the proposed five characteristics of positive design will be key in this respect.

\section{Interior Architecture: a Circumstantial Factor that contributes to Enabling Activities}

Most of the time, a building or interior as such cannot make a person happy. Architecture or interior architecture relate to a circumstantial factor (see Figure 1) which can contribute to a person's happiness via the fact that an architect or interior architect designs a particular context wherein activities can take place or can be organized which possibly can contribute to a person's happiness. In the view of different researchers from positive psychology (Lyubomirsky et al., 2005; Lyubomirsky, 2007; Lyubomirsky and Layous, 2013), intentional activities appear to be the best possible way for people to work on their happiness. Translating these insights to interior architecture implies that being happy in an environment has to do with what people who reside in a particular interior environment are able to do with and in that environment, or, put differently, how the environment enables them to do something meaningful, or something that adds meaning and pleasure to their life. In this respect, interior architects can be considered as important mediators in the relationship between a person and the interior environment wherein this person resides, as it is interior architects' task to design interior spaces which allow to accommodate and enable users to undertake activities that contribute to their happiness. Designers' role here is not to be neglected, as they need to truly make the design of a space wherein people will reside, live and work and 'do' activities. This is all the more important taken into account that interior spaces are 'inescapable'; we all need to reside in them. As such, they are to be considered as an important context for happiness-enhancing strategies.

Designing inspiring contexts where people are enabled to flourish is particularly challenging, because it requires a designer to truly empathize with the future users of the concerned context. Sometimes these users will concern an individual or a small family, where empathizing with the future user is rather clear-cut: in such contacts, the designer clearly has the possibility of truly having a close contact and relationship with his clients. At other times however, interior architects will be asked to develop a design for a future health care facility, a retail environment, or an office environment, for example. Empathizing with users in such projects is truly challenging (and not always straightforward, as discussed above; see also Sloane, 2014; Mitsui \& Nagai, 2014; Verhulst et al., 2016; Steen, 2016), as interior architects are then required to dive into the worldview of the concerned target group, get to know future users, their needs and wants, and have to do a truly valuable and meaningful effort in trying to combine these different sources of input into a significant interior architectural concept that 
can appeal and answer to the involved stakeholders' goals and ambitions in terms of their flourishing.

There is a huge challenge in further exploring how interior architects can design spaces in such a way so that they can function as a generous, inspiring and fruitful context wherein people can set up meaningful activities that enable them to work on their happiness. In what follows, we formulate our first attempts in taking up this challenge.

\section{Positive Design in Interior Architecture: selection of projects}

A possible way for an architect or interior architect to aim for the design of contexts that enable people to flourish, is focusing on developing a designerly translation of happiness-enhancing strategies as discussed above. Recently, we started to investigate if and how these strategies can be translated into positive interior architectural design in order to gain insight in the contribution that interior architecture can have in providing a 'platform' that offers people the possibility to actively work on their subjective wellbeing. Therefore, in this section, two student projects demonstrate how interior architecture can contribute to people's wellbeing.

These projects were selected firstly, because they concern graduation projects from master students in interior architecture ${ }^{1}$. Second, taken into account that in our view, design for wellbeing can have important repercussions and be a true added value for a diverse range of interior environments, projects were selected which concerned the design of very different architectural typologies: we discuss design projects for a revalidation center and a youth center. These projects are examples which illustrate the diverse scope of environments which interior architects encounter in their daily practice. Thirdly, it is self-evident that the design process of each of the selected projects was explicitly focused on designing for subjective wellbeing. Fourthly, in each project, a selection of happiness-enhancing strategies (see Figure 2) and the characteristics of positive design (i.e., balance, possibility-driven, personal fit, active user involvement, means for long-term impact) were taken into account when making particular happiness-enhancing strategies concrete. As the analysis below will demonstrate, for each one of them, this design approach added value to the design process and end product.

The projects discussed below are the result of a 'Research by Design' methodology, a research approach that is omnipresent in architecture and interior architecture. When performing research by design, the very act of designing is the key to developing understanding and contributing to knowledge development (Verbeke, 2013). In research by design, spatial possibilities involving different actors' sensibilities are explored, resulting in design output that bridges the possible gap existing between researchers in architecture and interior architecture, and practitioners in these disciplines.

\footnotetext{
${ }^{1}$ Graduation projects are the 'master design projects' which master students in interior architecture develop in their final year. In Belgium, the training program of interior architecture concerns 3 bachelor years +1 master year. The involved students' projects took 21 ECTS scores in their total program of 60 ECTS scores in the master year.
} 


\section{Revalidation center children's ward}

The master student in interior architecture focused her graduation project on the redesign of a revalidation center which accommodates children and youngsters who suffer from chronical respiratory and neurological illnesses.

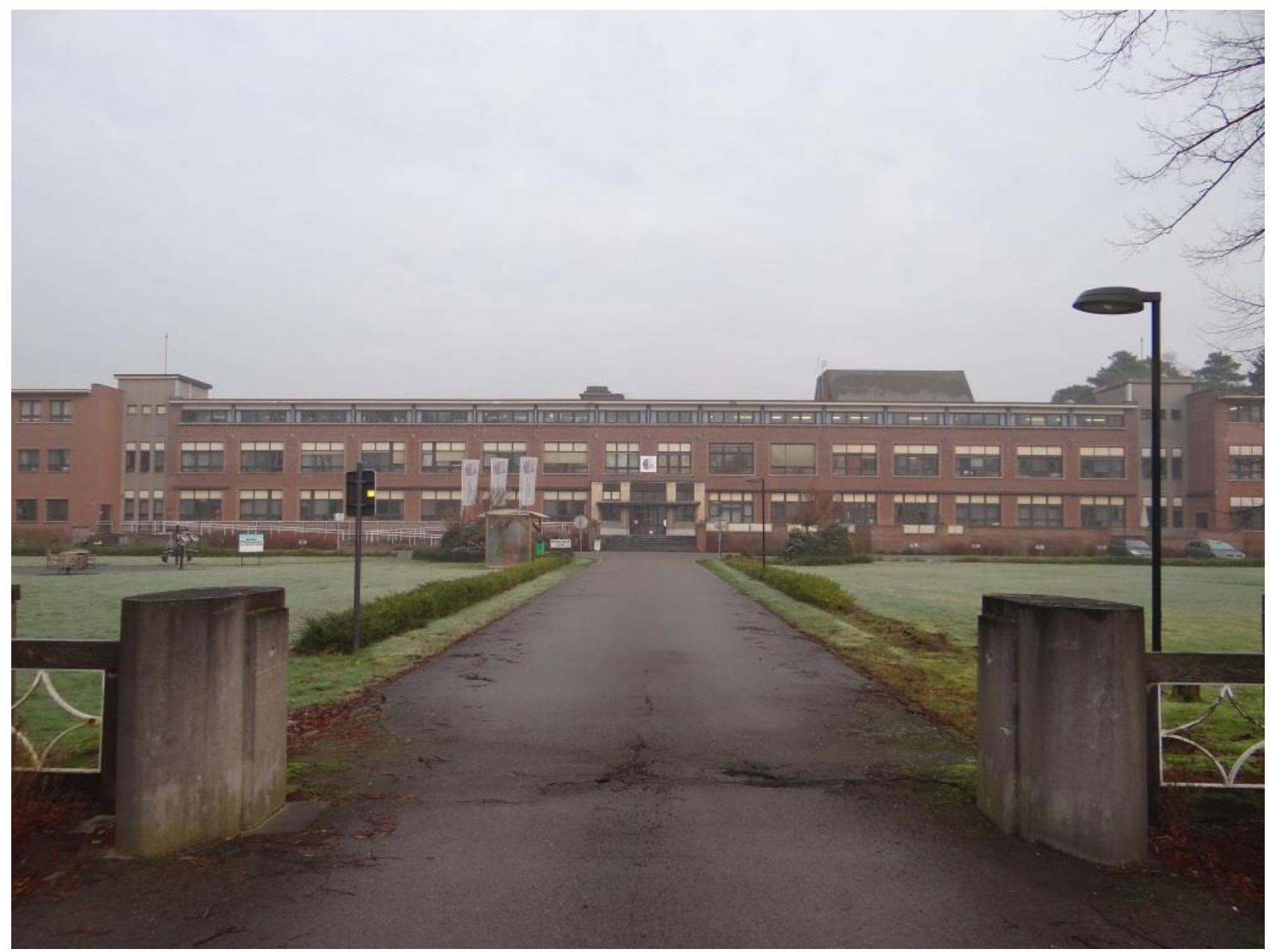

Figure 3. Revalidation centre Pulderbos

Source: Strackx, 2016

The revalidation centre (see Figure 3) was initially set up in 1939 as a preventorium. Throughout the years, it has been rebuilt and extended several times, following the continuous growth of medical evolutions and technologies. Today, this has resulted in a patchwork of building sections, all glued together, aiming to offer a warm house to its residents. However, this piecemeal, set up with the best possible intentions, struggles with various issues, and it is clear the centre lacks architectural and interior design initiatives that can trigger residents to undertake meaningful activities contributing to their wellbeing. Figures 4 and 5 give an illustration of the current condition of a private room and a therapy room at the location. 


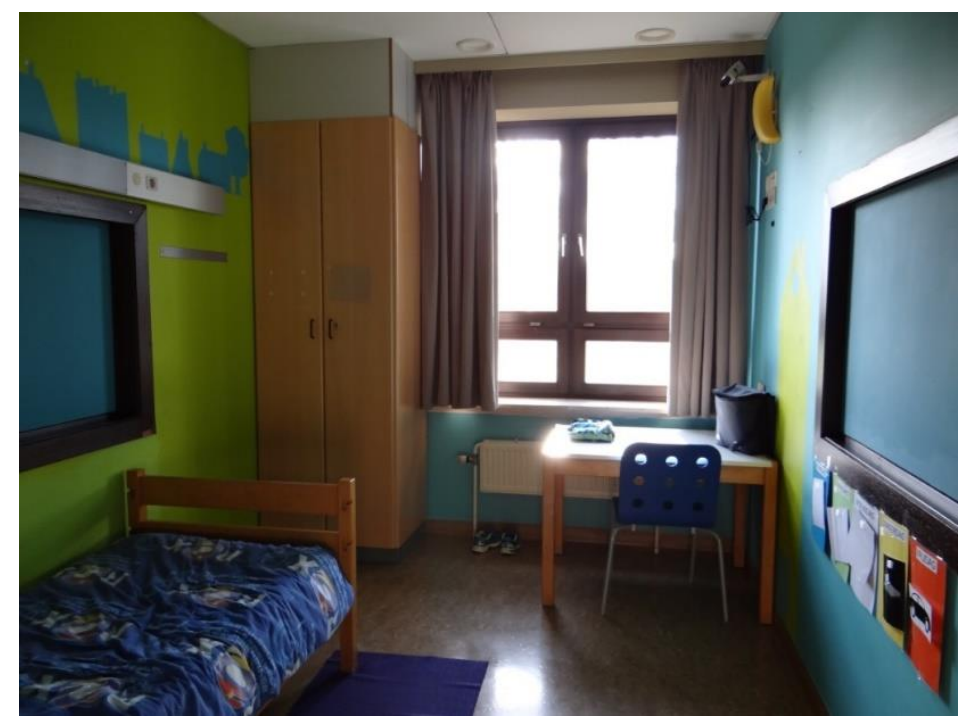

Figure 4. Interior private room, 'before scenario'

Source: Strackx, 2016

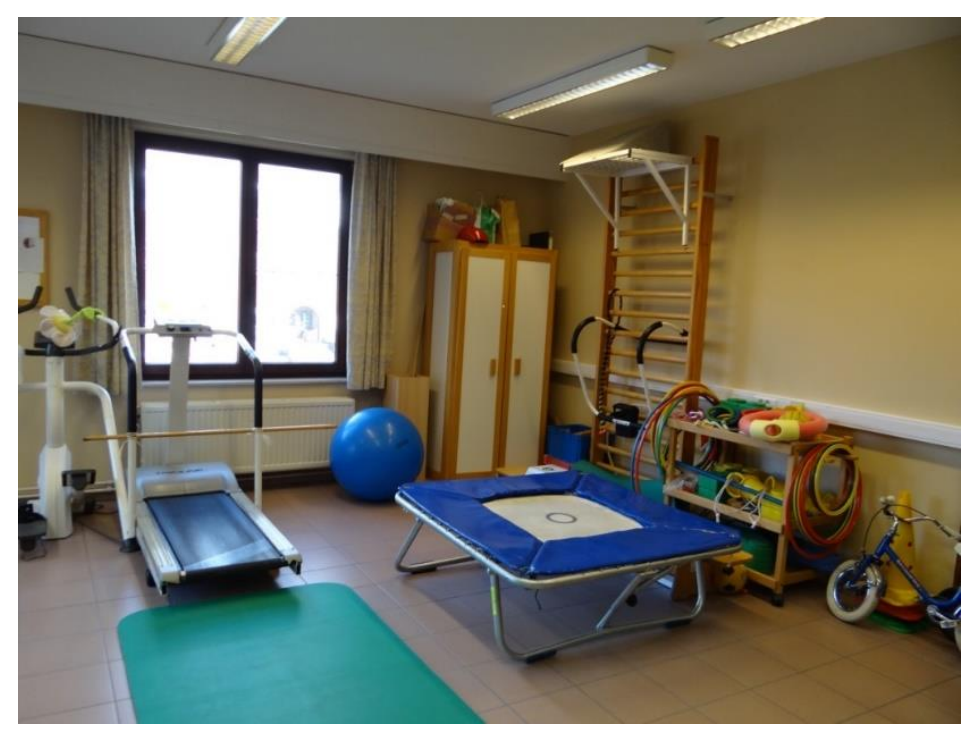

Figure 5. Interior therapy room, 'before scenario'

Source: Strackx, 2016

In her project, the student investigated how the opportunities and challenges which currently exist and which she could distillate from performing research on the site could be tackled, and how architecture and interior architecture can stimulate people residing here to work on their wellbeing. In elaborating each of the happiness-enhancing strategies this student worked on (see below), each of these opportunities and challenges will be discussed in more detail.

From the very start of her project onwards, the student embraced her topic; she knew the site very well as she resided at the center a long time during her proper childhood. Taking into account her proper experiences as well as building forth on insights which accumulated after her in-depth interviews with four children and youngsters currently living at the site as well as with four members 
of personnel working at the site, led her to formulating and developing particular design interventions.

In deciding on the key focus of her design project, which focused on children and young people between 6 and 21 years who all encounter serious respiratory deficiencies, self-reliance was a key issue. As she knew from her proper experiences as well as by residing again for some days at the site for her research purposes, young patients highly value their private rooms in the center. From the moment children are aged six onwards, they often start primary school, and therefore also at the revalidation center, their private room becomes more important as a host space for making homework, welcoming family and visitors in private circumstances, doing homework, etc. In her design project, the student focused in particular on the design of children's private rooms, therapy rooms and places where activities for various age groups could be hosted. Four happiness-enhancing strategies (marked in grey in Figure 6) were key for her in developing her design:

\begin{tabular}{|l|l|l|}
\hline Expressing gratitude & Cultivating optimism & $\begin{array}{l}\text { Avoiding overthinking } \\
\text { and social comparison }\end{array}$ \\
\hline $\begin{array}{l}\text { Practising acts of } \\
\text { kindness }\end{array}$ & $\begin{array}{l}\text { Nurturing social } \\
\text { relationships }\end{array}$ & $\begin{array}{l}\text { Developing strategies } \\
\text { for coping }\end{array}$ \\
\hline Learning to forgive & $\begin{array}{l}\text { Increasing flow' } \\
\text { experiences }\end{array}$ & Savouring life's joys \\
\hline $\begin{array}{l}\text { Committing to your } \\
\text { goals }\end{array}$ & $\begin{array}{l}\text { Practising religion and } \\
\text { spirituality }\end{array}$ & $\begin{array}{l}\text { Taking care of your } \\
\text { body }\end{array}$ \\
\hline
\end{tabular}

Figure 6. Happiness-increasing strategies in project of revalidation centre

(i) Nurturing social relationships: children who need to stay in the centre, are being taken away from their home environment. For the duration of therapy needed, they get a 'new home', which inevitably has consequences in terms of how often they can see and physically connect their family members, friends, etc. At Pulderbos, the guiding team tries to answer these changing circumstances by creating 'living groups' so that children of similar ages come together and 'live' at the centre by adapting to a similar day-planning as children would follow under usual circumstances: together with their peers, whom they get to know quickly at the centre (because the group of patients per living group is relatively small), they awaken together at the same hour, have breakfast together, relax together, ... just as they would do in a regular home/school environment. Evidently, family and regular friends are also highly welcome at the centre, so that social relationships can still be nurtured. In order to foster this strategy, the student foresaw more spaces and facilities in her design to enable patients to properly welcome and connect to family and friends (in private rooms as well as in the existing communal spaces). What she also did in her design to foster this aspect, is integrating various multimedia in each patient room (allowing IPad, mobile phone, laptop, ...) so that patients could easily remain digitally 
connected with their loved ones. Evidently, these devices would also allow the patient to nurture social relationships built up with fellow patients while residing at the revalidation centre. Evidently, in each private room of the revalidation centre, all necessary and functionally relevant medical apparatus was present, but was 'hidden' in the cupboard which she designed and which surrounded the bed (which could also be easily adapted in terms of height). In this sense, different designerly efforts were combined to enable the patient to have an easily adaptable room, fully equipped private room which could easily be personalized and decorated (see Figures 7 and 8).

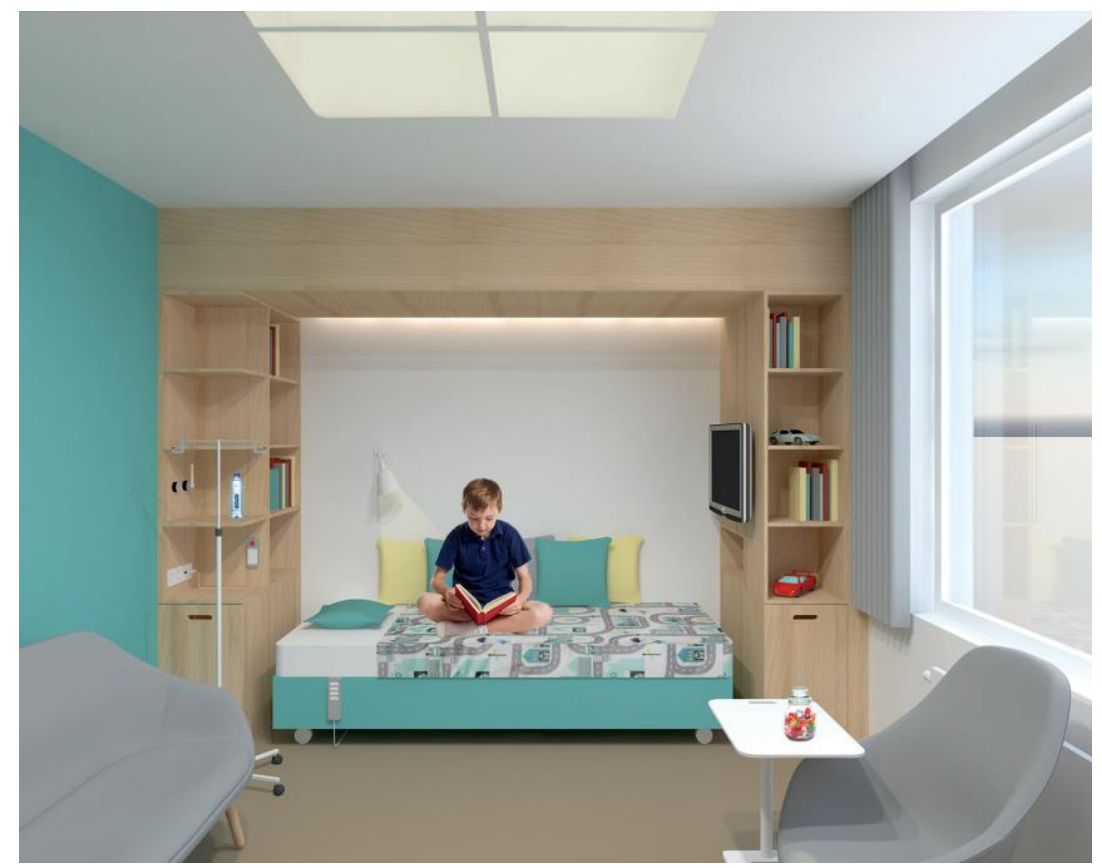

Figure 7. Interior private room, 'after scenario'

Source: Strackx, 2016

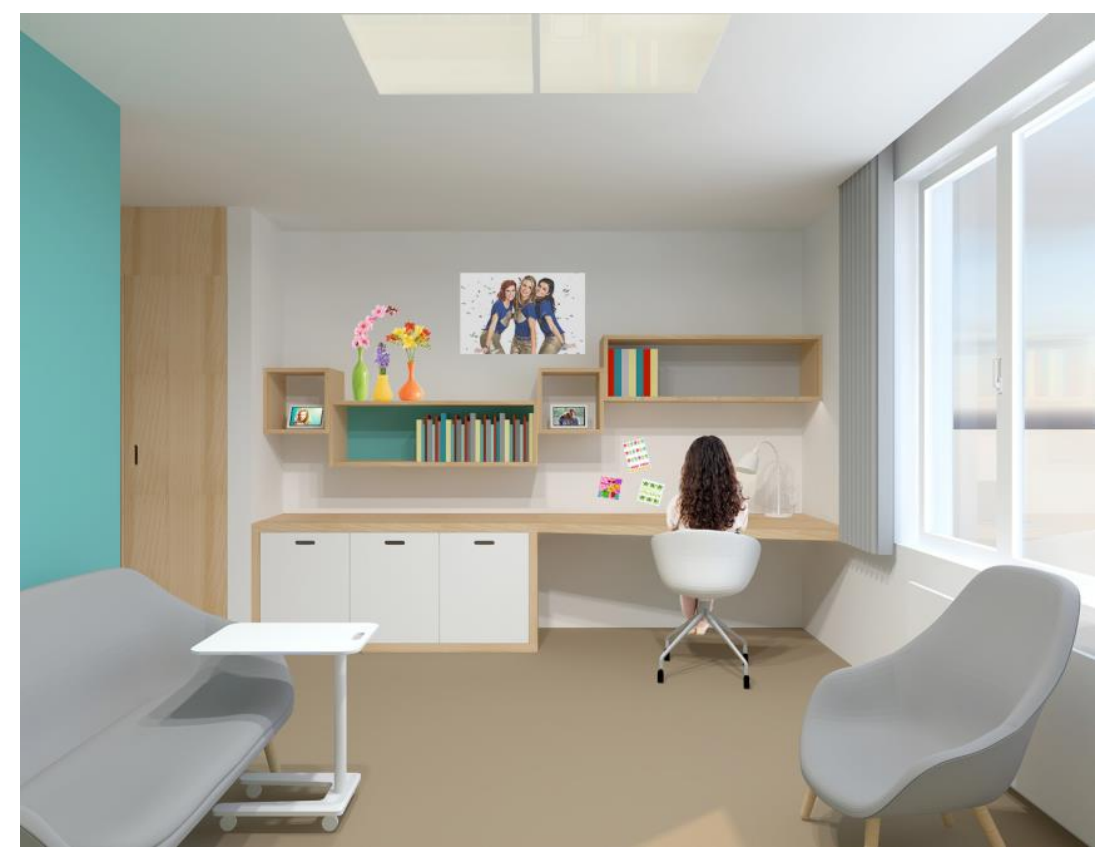


Figure 8. Interior private room, 'after scenario'

Source: Strackx, 2016

(ii) Increasing flow experiences: children who reside at the revalidation centre, have a severe respiratory or neurological deficiency which highly limits them in their daily activities. In developing a daily program with and for these patients, it is important to focus on the abilities of children so as to increase the possibility of flow experiences. It is clear that the design of the interior and exterior environment can contribute in this respect. For instance, what was clearly a problem in the revalidation centre today, concerns the actual organisation of functions at the site. Spaces for education, therapy, etc. are literally spread over the whole site, implicating various movements for the patients and staff, taking a lot of time and effort. In her design, the student organized these functions in clusters to better answer actual needs of patients and personnel and to come to a clear overview. In reorganizing the site, she also linked the different parts with new 'paths' which don't have any stairs but which are sloping whenever necessary - which is challenging and inviting to go through for all patients, whether they'd be in a wheelchair or not. At these pathways, she also designed interesting spaces to meet up, so that children could share stories with others here.

(iii) Committing to your goals: one of the key goals for children who reside at the revalidation centre, is to safeguard or increase their self-reliance, so that they can learn to live as independently as possible. Small interior adaptations can prove to be key in this respect: for instance, the student thoughtfully integrated automatic doors throughout the building, so that children in a wheelchair wouldn't need to depend on others to help them circulate from one space to the other. The bathrooms which she also developed for several children's private rooms, also had a door which can turn both inwards and outwards, allowing for instance a nurse to easily enter the bathroom in case a child would fall.

(iv) Taking care of your body: it is clear that for children who need to recover at the revalidation centre, taking care of their body is a key issue. In practice, every child gets a tailor-made revalidation program which answer the child's actual needs, wherein medical treatment, therapy and education are integrated. Issues regarding physical as well as mental health are covered. As these young patients spend a lot of time indoors, next to their private rooms, also the interiors of the therapy spaces were questioned by the master student. These need to be able to function well, and should be ergonomic in use, both for patients as for the involved personnel. Given the young age of the patients, the therapy rooms also should be inviting and playful, offering variety in opportunities for children to do exercises and learn to take care of their body, but without distracting them too much. Here again, in her design, next to the typical training modalities which these kinds of rooms need, the student made use of multimedia to enrich the experiences of patients who would need to exercise here. Via various screens, she enabled to virtually show a situation to which the training program could be aligned (e.g., a forest, a residential area) (See 
Figure 9). In spaces for ergotherapy, she foresaw magnetic walls as an interesting stimulus to allow therapists to work on the fine motoric skills of young patients in an intriguing and appealing way (see Figure 10). Enabling children to take care of their body was also a key issue in the student's design of the private room, where she (in most private rooms) foresaw a proper bathroom (in contrast to the current situation at the revalidation centre). The presence of this space where all facilities are present, stimulates the self-reliance of children to take care of their body and also gives them more privacy, which is definitely an issue when pupils get into puberty.

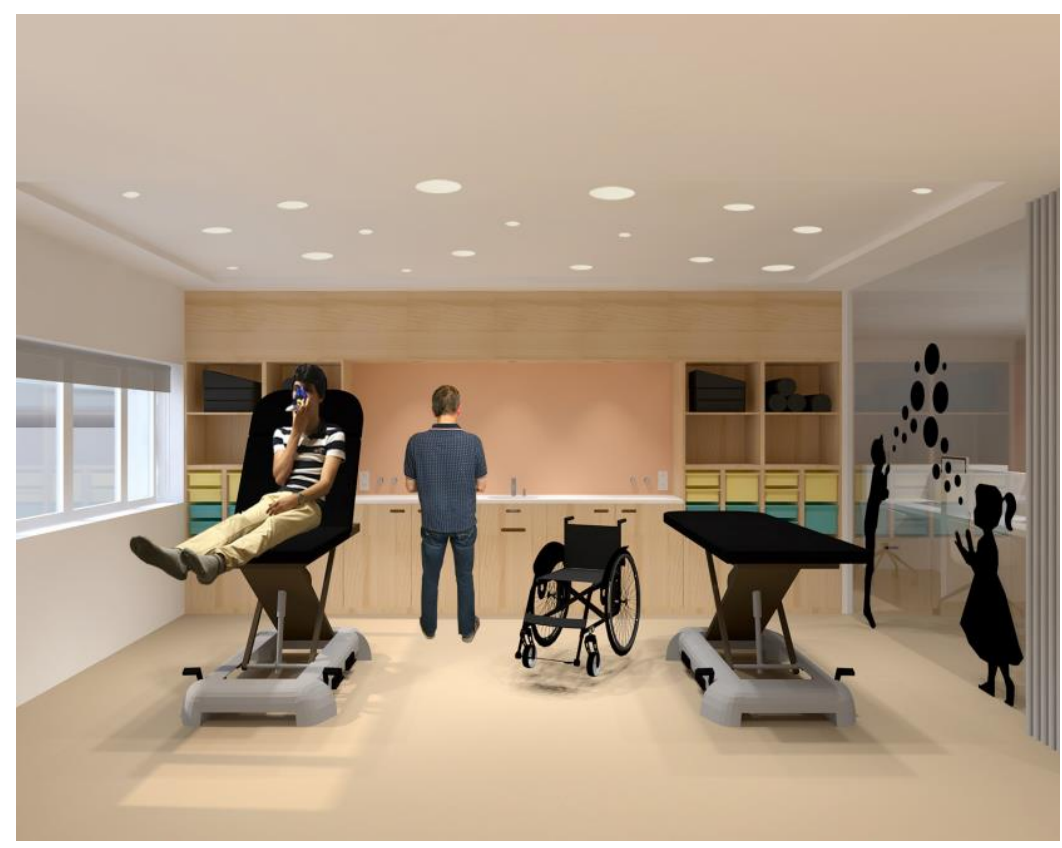

Figure 9. Interior therapy room, 'after scenario'

Source: Strackx, 2016 


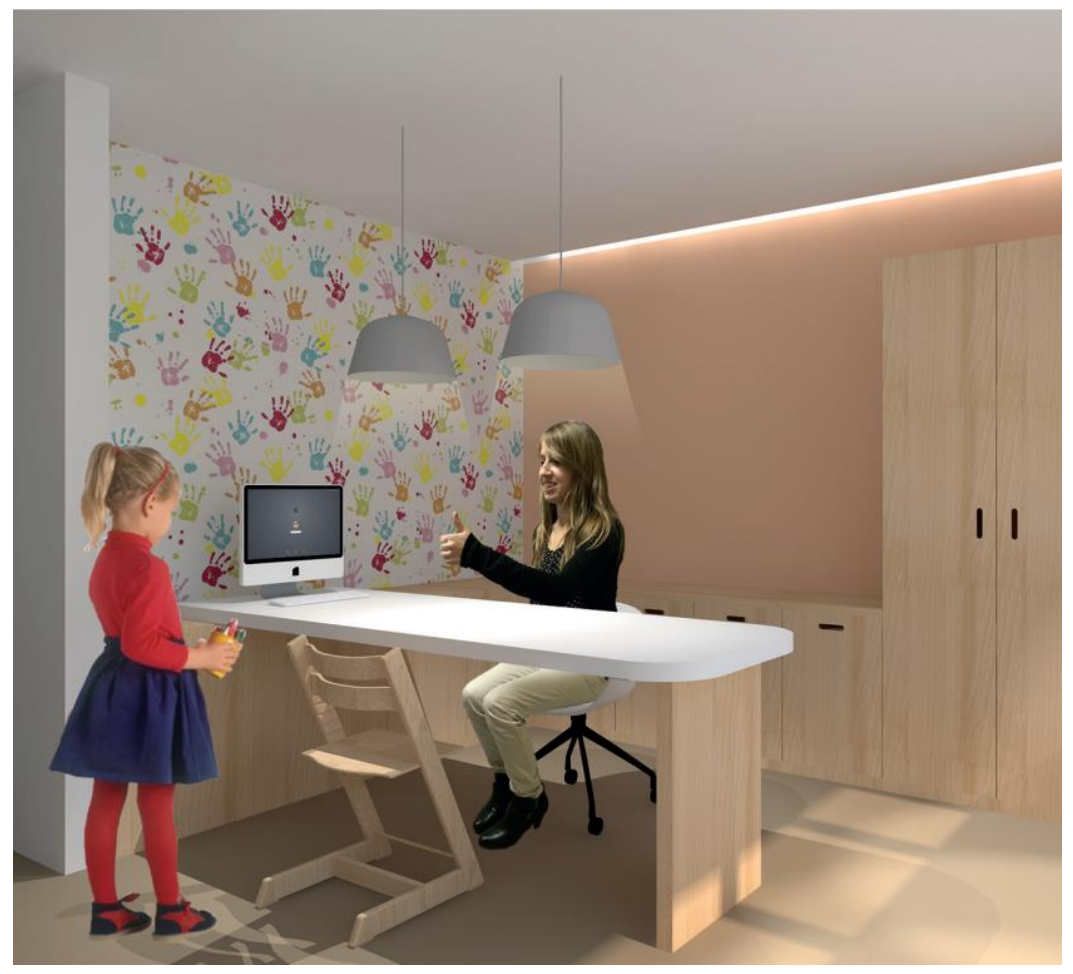

Figure 10. Interior therapy room, 'after scenario'

Source: Strackx, 2016

Investigating the introduction of domotics in the student's design project also demonstrates the characteristics of positive design. Regarding 'balance', the introduction of domotics allows the children to have pleasure (i.e., playing with the light button is always fun for children), but also contributes to their personal significance: here, technology enables children to work on their autonomy and independent functioning. Domotics also fosters virtues as children will feel more important and valuable when able to do these kinds of things by themselves. As to 'personal fit', the use of domotics is entirely consistent with the life world of the current generations of youngsters, who was the target group of the student's design project. Concerning 'long-term impact', as discussed before, the key goal that children who reside in the revalidation centre strive for, is self-reliance. The integration of domotics in their private room allow children to be able to put the light on themselves, which increases their responsibility and autonomy. In the long turn, such a (at first glance) small interior adaptation can signify a lot for the wellbeing of the involved youngster. Regarding 'active user involvement', the use of domotics in the private room of the young patients enables them for instance to turn the light in their room on/off, which triggers their development and independence. Finally, as to the aspect of 'possibility-driven', it is clear that being able to decide on the functioning of domotics in their private space enables children not only to decide to put the light on/out, but also enables them to create a particular atmosphere in their room. Here, technology offers various possibilities which can contribute to the wellbeing of the patients.

\section{A youth center in a multicultural neighborhood}

The master student who developed this project, had a particular interest in investigating how the 
design of a youth center could possibly add value to improving social relations between youngsters from a very diversified cultural background, all living together in a particular multicultural city quartier. Based on her proper experiences and after performing observations in primary and secondary schools in the concerned neighborhood, she learned that youngsters here tended to group per cultural background; very few intercultural and mixed gender social relations could be noticed.

For her master project, she transformed a key building in the neighborhood where she developed her project (see Figure 11) into a youth center where young people could come by and engage in various kinds of activities in order to meet, get to know other better and learn from one another. The building which she worked on was known by everyone in the neighborhood as a place where people in earlier ages would come together to meet up and share experiences and have a lot of talks and discussions. Currently, only a small part of the building was still in use for a local youth movement, but most of it was in a bad condition (see Figure 12a, b, c). Therefore, local government also recently decided that the youth movement needed to move out of the building on a short notice.

Via her project, she aimed to be able to stimulate young people in learning to cope with others in a respectful way and to engage in activities which are meaningful to them and that contribute to their wellbeing, so that in the end, her design project would re-connect with the original function and meaning of the building at this particular place.

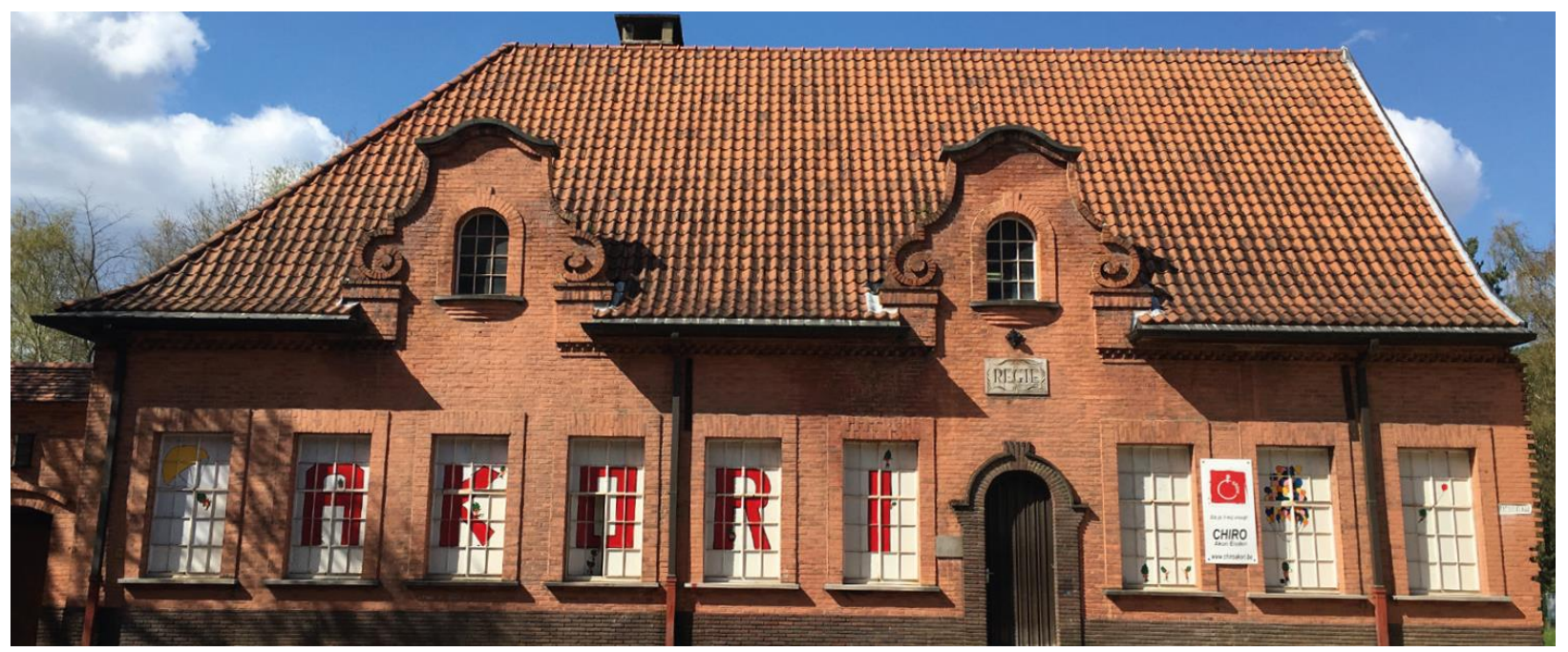

Figure 11. Regiegebouw Eisden

Source: Vanhelden, 2017 

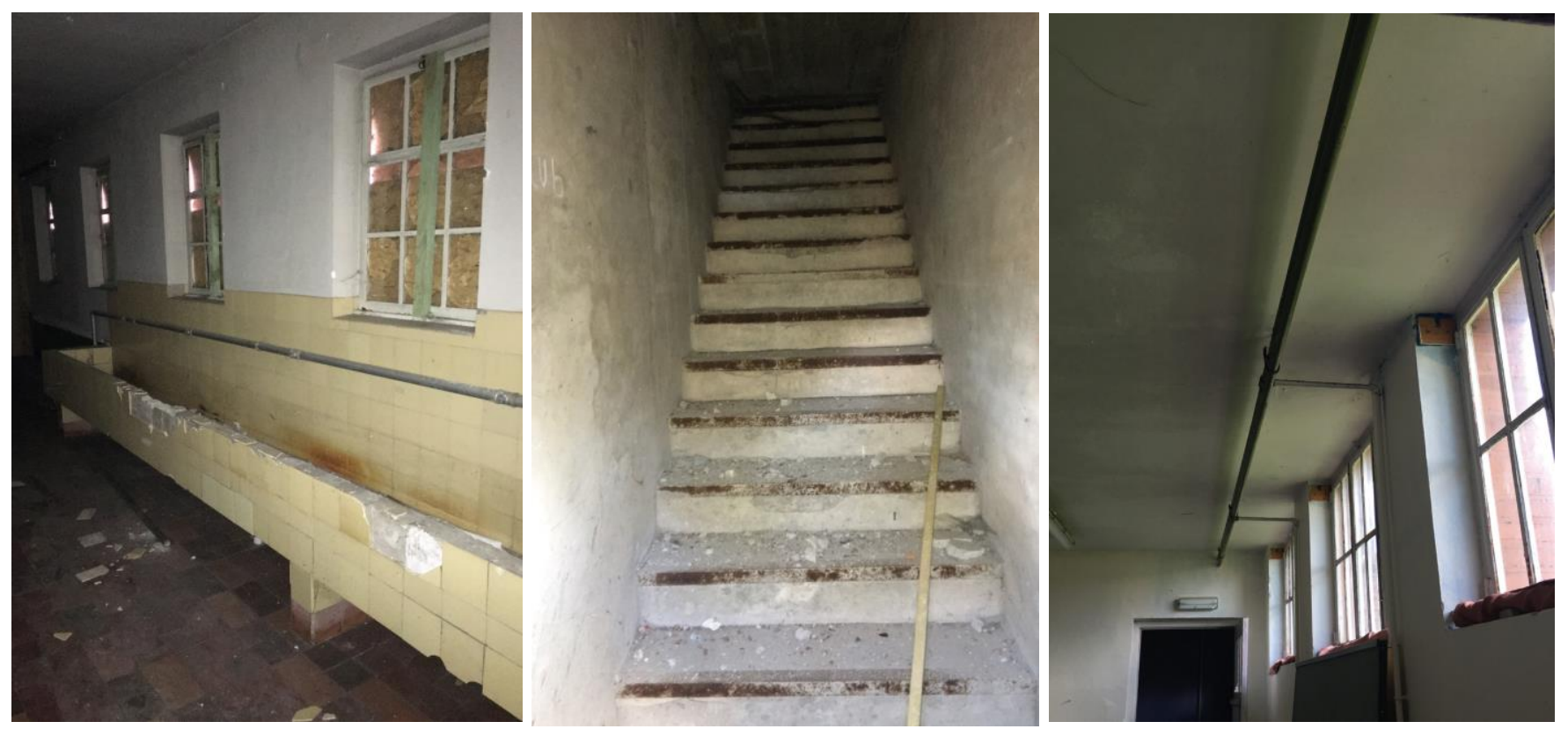

Figure 12a,b, c. Interior Regiegebouw Eisden, 'before scenario'

Source: Vanhelden, 2017

From the start of her master in interior architecture onwards, she wanted to dive into this subject and come up with refreshing insights with which she could propose an alternative concept for a youth center that would 'work' in the 'difficult' neighborhood where she went to primary and secondary school and where she personally also encountered difficult situations in the past. One of the key choices the student made, was to choose a building really close to the surroundings schools to house her project. Her project aimed at youngsters from two age groups: 6-12 years, and 13-18 years. In her project, she envisioned to work with mixed groups, so that boys and girls needed to collaborate with each other in various activities which would be enabled at the chosen site. Her observations in the neighborhood and the surroundings schools learned her that this was a necessity, as both sexes seemed to avoid each other in daily conversations and activities. Four happiness-enhancing strategies (marked in grey in Figure 13) were key for her in developing her master design project:

\begin{tabular}{|l|l|l|}
\hline Expressing gratitude & Cultivating optimism & $\begin{array}{l}\text { Avoiding overthinking } \\
\text { and social comparison }\end{array}$ \\
\hline $\begin{array}{l}\text { Practising acts of } \\
\text { kindness }\end{array}$ & $\begin{array}{l}\text { Nurturing social } \\
\text { relationships }\end{array}$ & $\begin{array}{l}\text { Developing strategies } \\
\text { for coping }\end{array}$ \\
\hline Learning to forgive & $\begin{array}{l}\text { Increasing flow' } \\
\text { experiences }\end{array}$ & Savouring life's joys \\
\hline $\begin{array}{l}\text { Committing to your } \\
\text { goals }\end{array}$ & $\begin{array}{l}\text { Practising religion and } \\
\text { spirituality }\end{array}$ & $\begin{array}{l}\text { Taking care of your } \\
\text { body }\end{array}$ \\
\hline
\end{tabular}

Figure 13. Happiness-increasing strategies in project of youth center in multicultural neighbourhood 
Nurturing social relationships: it is important that young people learn to nurture, respect and cherish social relationships, as often, most youngsters do not necessarily reflect much about these kinds of things yet. Literally learning to embrace each other will be enabled in the student's design project, to foster feelings of intimacy, friendship and belongingness. In her design project, embracing each other will be introduced upon entrance of the space, during group talk and when closing the session. Also working on communication will be a key topic in the youth centre, so that young people learn to share thoughts and experiences, which fosters their abilities in enlarging their social networks and discussing a great diversity of topics. Linked to these challenges, she introduced space for guidance in homework in her design project, so that young people from the neighbourhood could be instigated to share their knowledge, talents and expertise with others and help them out. In the design of the youth centre, the student developed modular furniture that could be used throughout the building (see Figure 9). Her furniture could be used as seating elements or cupboards, but could easily be transformed into tables, enabling designing completely different spaces without much effort (see Figure 9). All furniture could be painted in different colours - she selected four colours which were used repeatedly throughout the building.

(ii) Practicing religion and spirituality: in the centre, youngsters will be enabled to learn more about different religions, their values and norms, their application in daily life, and respect these practices. In the youth centre, the student foresaw a space where youngsters can freely discuss in groups about different cultures and religions (without parents or other important religious stakeholders being present). In this space, she designed a cupboard where books regarding culture and religion were present, and again, the modular furniture she designed was present in the space to enable youngsters to discuss in a pleasant, appealing atmosphere.

(iii) Practicing acts of kindness: in her design project, it was envisioned for youngsters to work on this strategy in different ways. Every week, every youngster would need to engage in at least 3 acts of kindness for somebody else. Every week, these acts would be discussed in group. There would also be guidance for youngsters in order to train them how to engage in this strategy in practice, and how to deal with it. Next, she envisioned to train youngsters as 'buddies' who could welcome new students in the surroundings schools so as to welcome them in a proper way. Interviews and talks she had with youth workers and relevant actors in schools and religious gathering points in the neighbourhood learned her that these issues would be welcome, but at the same time very challenging to try to connect with the target group she envisioned for her project. In her design project, she translated these challenges in the design of multifunctional spaces in the youth centre which could be easily transformed from big rooms to smaller spaces to create more intimacy and enable people to talk more freely and more open, and to share experiences and/or to help each other out (see Figure 10). In these spaces, boards would be hanged to enable youngsters to 'communicate' about these acts of kindness by using words, collages, drawings, 
sketches, ... and exposing these. In this way, also youngsters' creative talents could be boosted.

(iv) Learn to forgive: as the youth centre will be integrated in a multicultural neighbourhood, full of challenges regarding living together and embracing diversity, this strategy was also key to the master student. In her design, she also wanted to foster youngsters to develop conflict resolution skills, learn hope to cope with bullying, and learn to forgive each other. Therefore, spaces enabling group discussions as well as more intimate spaces (to solve conflicts) with the modular furniture were necessary in her project to foster this happinessenhancing strategy.
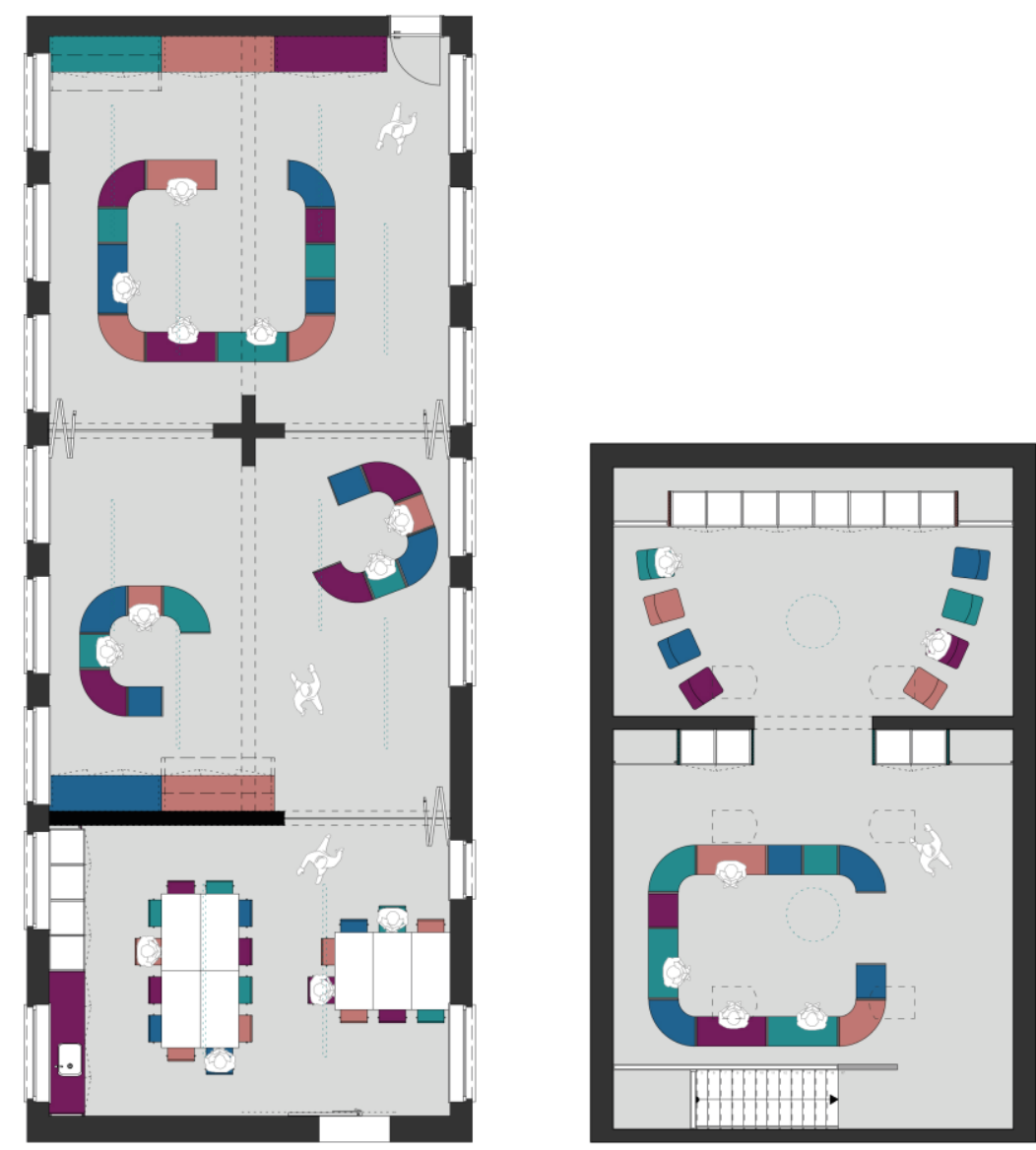

Figure 14. Multifunctional spaces and modular furniture, 'after scenario' Source: Vanhelden, 2017 


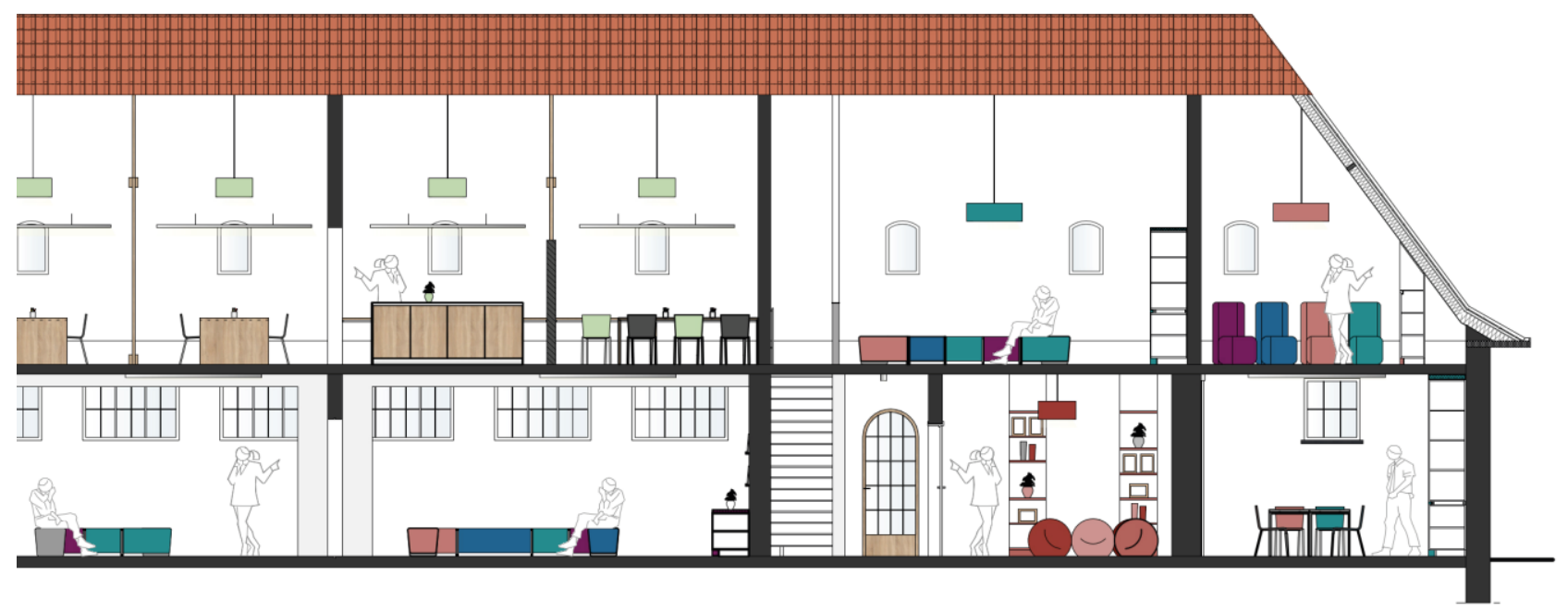

Figure 15. Right volume cut of building, 'after scenario'

Source: Vanhelden, 2017

Focusing on the introduction of the modular furniture in the student's design project also demonstrates the characteristics of positive design. Regarding 'balance', it is clear that the formation and easy transformation of spaces via using modular furniture offers pleasure to youngsters, but also helps to contribute to personal significance and virtues they strive for. When the modular furniture enables them to create intimate spaces, it is easier to discuss about particular topics that are not selfevident for youngsters or to share experiences or knowledge they would not easily share in other circumstances. As to 'personal fit', the modular furniture could be pointed in different colours which combination appeals to youngsters; also the fact that they could (assist in the) re-organization of spaces will appeal to them. Concerning 'long-term impact', the student's project strived for the building to bring together local people again, so that they could unite and bond. Regarding 'active user involvement', the program of activities the student envisioned clearly demonstrates how people of the neighbourhood would be involved in her project, which would also be 'possibility-driven', focusing on the provision of various kinds of activities people could engage in, in order to work on their wellbeing.

\section{Discussion}

To date, there are architects and interior architects who take considerations regarding wellbeing into account when developing new design concepts for particular projects, but most of the time, they do this rather intuitively and implicitly (Steen, 2016). With our approach, we aim to formulate explicitly a possible way that interior architects might use in future projects when aiming to work on the wellbeing of the target group for whom they work. The analyses of two projects demonstrated that the application and interior architectural translation of the happiness-enhancing strategies (Lyubomirsky, 2007) and characteristics of positive design (Desmet $\&$ Pohlmeyer, 2013) are valuable and novel ways to design for wellbeing in interior architecture. Focusing the spatial design process first, on triggering opportunities for people (instead of focusing on the solution of particular problems) and second, on creating possibilities which can enable people to engage in activities that 
can foster their subjective wellbeing adds knowledge to the body of theory in interior architecture. It entails an active engagement of (future) users, and empowers them to become participants in the design process who can help steer the process in order for it to become as meaningful as possible for the involved users in the long run.

The discussed projects demonstrated how eight of Lyubomirsky's (2007) twelve happiness-enhancing strategies were translated into interior architectural interventions in the concerned buildings. One strategy (i.e., nurturing social relationships) was chosen for both projects, showing the possible diversity in interior architectural translation in this respect. The student's design of the revalidation center demonstrated how working on this strategy resulted in her foreseeing more spaces and facilities to enable patients to properly welcome and connect to family and friends (in private rooms as well as in communal spaces). She also integrated various multimedia throughout her design project, so that patients could easily continue to nurture the social relationships via different kinds of digital connections.

In the design of the second project, the youth center, the student developed and proposed modular furniture to be used as an instigator of nurturing social relationships. This interior architectural translation of Lyubomirsky's strategy is very different from the one proposed in the first project, but in theirselves, both translations connect really well with the needs and wishes of both the building and the users involved in both projects, which were truly diverse. This demonstrates the need for a true empathic stance of the involved interior architects. At the same time, this diversity and 'openness' when designing for wellbeing is also an important issue in interior architecture, where designers highly value creative freedom, to safeguard they can come up with their own inspiring and appealing designs.

The approach of the design process applied in both projects demonstrates how design for wellbeing differs from other approaches in interior architecture and design in general that also place the user at the heart of the design process. As there is very few research present in interior architecture to date on the topic of design for wellbeing, it is our aim that this approach offers first concrete levers for architects and interior architects to start incorporating these important thoughts and concerns into their design projects. The analyses performed also demonstrate that it is important to always take "specifics" with respect to the concerned design discipline into account when trying to introduce a renewing design approach, such as design for wellbeing, into design practice. For instance, it is clear that interior architecture differs from product and industrial design in various aspects (for instance, think about the issue of 'ownership' of a design, its 'permanence', the related financial investment, etcetera - see Petermans \& Pohlmeyer, 2014), which can impact on the way and the pace wherein design for wellbeing is being introduced in diverse design disciplines. 


\section{Conclusion}

The purpose of this paper was firstly, to demonstrate that it is relevant for interior architecture to design for subjective wellbeing, and secondly, to show how interior architects can be triggered to design for wellbeing.

Lyubomirsky's happiness-enhancing strategies (2007) and Desmet and Pohlmeyer's characteristics of positive design (2013) have been starting-points in this respect. The two student projects that were discussed, show first attempts in our exploration of how interior architects can design spaces in such a way so that they can function as a fruitful context wherein people can set up meaningful activities that trigger them to work on their wellbeing.

Evidently, many more case studies could be performed wherein other happiness-enhancing strategies are translated in an interior architectural way, but with the choice for this particular sample of student projects, we aimed to provide a first insight into the diverse scope of interior environments that have the possibility to enable people to undertake meaningful activities that contribute to their wellbeing. These kinds of environments could definitely 'profit' from designers who consciously reflect about introducing design for wellbeing elements into their interior designs.

It seems interesting for future research firstly, to elaborate about the value and meaning that the different happiness-enhancing strategies and characteristics of positive design can have for a wider array of interior environments. Secondly, future research could broaden the scope of participating designers. The two projects discussed reflect about design for wellbeing in recent projects of master students in interior architecture, but future research could definitely try to broaden this sample to actual design practice (although up to date, efforts to explicitly design for wellbeing in interior architecture are relatively rare). Thirdly, future research could also choose for one typology in particular (e.g., housing for older persons), and dive more in-depth into this particular typology in an effort to find out how interior architects can be enabled to design environments wherein this particular target group of people is enabled to undertake activities that contribute to their wellbeing.

Fourthly, future research needs to investigate if principles and / or a framework can be developed that can help to train students in interior architecture and practicing interior architects how to design for wellbeing. First initiatives in this respect are present (see the work of Steen, 2016; Stevens et al., 2016a, 2016b; Stevens, 2018), but there is room for many more experiments. Finally, it seems highly valuable for future research to try to assess the impact that concrete design initiatives and interventions regarding subjective wellbeing trigger in users of a particular environment.

There is a whole path to go for research on design for wellbeing in interior architecture. But the challenges that face our society today make it all the more important to contribute the necessary attention hereto within the discipline, and thus to study if and how interior architects could contribute to the design of interior environments that enable people to undertake activities that contribute to their wellbeing. It is our hope that this paper is a valuable contribution in this respect. 


\section{References}

Bollnow, O. (2011). Human space. London: Hyphen Press.

Denson, M.G. (2017). Empathic design matters. In Kopec, D. (Ed.), Health and well-being for interior architecture (pp. 148-158). New York: Routledge.

Desmet, P. and Hassenzahl, M. (2012). Towards happiness: possibility-driven design. In M. Zacarias and J.V. de Oliveira (Eds.), Human-Computer Interaction: the agency perspective (pp. 3-27). Berlin: Springer.

Desmet, P. and Pohlmeyer, A. (2013). Positive design: an introduction to design for subjective wellbeing. International Journal of Design, 7(3): 5-19.

Diener, E. (2000). Subjective wellbeing: The science of happiness and a proposal for a national index. American Psychologist, 55, 56-67.

Edwards, C. (2011). Interior design. A critical introduction. Oxford: Berg.

Encylopedia Britannica (2013). Happiness and virtue. Retrieved July 7, 2014, from http://www.britannica.com/EBchecked/topic/464109/Plato/281699/Happiness-and-virtue.

Hassenzahl, M., Eckoldt, K., Diefenbach, S., Laschke, M., Lenz, E. and Kim, J. (2013). Designing moments of meaning and pleasure. Experience design and happiness. International Journal of Design, 7(3), 21-31.

Lee, J., Je, H. \& Byun, J. (2011). Wellbeing index of super tall residential buildings in Korea. Building and Environment, 46, 1184-1194.

Lykken, D. and Tellegen, A. (1996). Happiness is a stochastic phenomenon. Psychological Science, 7(3), 186-189.

Lyubomirsky, S., Sheldon, K. and Schkade, D. (2005). Pursuiing happiness: the architecture of sustainable change. Review of General Psychology, 9(2), 111-131.

Lyubomirsky, S. (2007). The how of happiness: a new approach to getting the life you want. New York: Penguin Books.

Lyubormirsky, S. and Layous, K. (2013). How do simple positive activities increase wellbeing? Current Directions in Psychological Science, 22, 57-62.

Mitsui, Y. \& Nagai, Y. (2014). Human-centred architectural design: a novel design method focusing on prospective episodic memories. Journal of Design Research, 12(3), 221-238.

Petermans, A., Van Cleempoel, K. \& Janssens, W. (2013). A holistic framework for conceptualizing customer experiences in retail environments. International Journal of Design, 7(2), 1-18.

Petermans, A. \& Pohlmeyer, A.E. (2014). Design for subjective wellbeing in interior architecture. In Proceedings of the 6th Symposium of Architectural Research 2014: Designing and Planning the Built Environment for Human Well-Being, p. 206-218.

Petermans, A. \& Nuyts, E. (2016). Happiness in place and space: exploring the contribution of architecture and interior architecture to happiness. In Desmet, P.M.A., Fokkinga, S.F., Ludden, G.D.S., Cila, N. \& Van Zuthem, H. (Eds.). Proceedings of the Tenth International Conference on Design and Emotion: Celebration \& Contemplation, September 27-30, 2016, Amsterdam, The Netherlands, The Design \& Emotion Society, p. 114-122.

Seamon, D. (2012). Physical and virtual environments: meaning of place and space. In B. Schell and 
M. Scaffa (Eds.), Willard and Spackman's Occupational Therapy (pp. 202-214). Philadelphia: Wippincott, Williams and Wilkens.

Seamon, D. and Gill, H. (2015). Qualitative approaches to environment-behavior research: understanding environmental and place experiences, meanings and actions. In Gifford, R. (Ed.), Research Methods in Environment-Behavior Research. New York: Wiley/Blackwell.

Seligman, M. (2011). Flourish. New York: Free Press.

Sheldon, K. and Lyubomirsky, S. (2007). Is it possible to become happier? (And if so, how?) Social and Personality Psychology Compass, 1(1), 129-145.

Sin, N. and Lyubomirsky, S. (2009). Enhancing wellbeing and alleviating depressive symptoms with positive psychology interventions: a practice-friendly meta-analysis. Journal of Clinical Psychology in session, 65(5), 467-487.

Sloane, M. (2014). Tuning the space: investigating the making of atmospheres through interior design practices. Interiors, 5(3), 297-314.

Smith, D., Metcalfe, P. and Lommerse, M. (2012). Interior architecture as an agent for wellbeing. Journal of the HEIA, 19(3), 2-9.

Steen, M. (2016). Organizing Design-for-Wellbeing projects: using the capability approach. Design Issues, 32(4), 4-15.

Stevens, R., Petermans, A. and Vanrie, J. (2016a). Bit by byt towards a contemporary conjoint interior: from Dom Narkomfin to a new social condenser. Interiors, DOI: 10.1080/20419112.2016.1201908.

Stevens, R., Petermans, A. and Vanrie, J. (2016b). Design for Human Flourishing in Architecture: Programmatic writing as a way to design socio-cultural affordances. Proceedings of the 10th International Conference on Design and Emotion Celebration and Contemplation (pp. 90-99).

Stevens, R. (2018). A launchpad for design for human flourishing in architecture. Theoretical foundations, practical guidance and a design tool (PhD thesis). Hasselt: Hasselt University Press.

Strackx, A. (2016). Welbevinden en interieurarchitectuur: herbestemming van het revalidatiecentrum Pulderbos (master thesis). Hasselt: Hasselt University.

Vanhelden, L. (2017). Het JOC: multicultureel jong. Herbestemming van het regiegebouw in Eisden Tuinwijk tot een jeugdontmoetingscentrum (master thesis). Hasselt: Hasselt University.

Veenhoven, R. (2011). Greater happiness for a greater number. Is that possible? If so, how? In K. Sheldon, T. Kashdan and M. Steger (Eds.) (2011). Designing positive psychology: taking stock and moving forward. Oxford: Oxford University Press.

Veenhoven, R. (2016). What we have learnt about happiness. Classic qualms in the light of recent research. In F. Maggino (Ed.) (2016). A life devoted to quality of life (pp. 151-170). Cham: Springer. Verbeke, J. (2013). This is research by design. In Fraser, M. (Ed.), Design research in architecture: an overview (pp. 137-160). Farnham: Ashgate.

Verhofstadt, E., Bleys, B. \& Van Ootegem, L. (2015). Reference-dependency of happiness ratings. Journal of Happiness Studies, 16, pp. 1437-1454.

Verhulst, L., Elsen, C. \& Heylighen, A. (2016). Whom do architects have in mind during design when users are absent? Observations from a design competition. Journal of Design Research, 14(4), pp. 
368-387.

Welzer, H., Giesecke, D. and Tremel, L. (2014). Futurzwei. Fischer Taschenbuch. 